\title{
How to Improve Communicative Competence in a Lingua Franca: Reasons and Practices
}

Shigenori Wakabayashi*

Department of English Studies, Chuo University, 742-1 Higashi Nakano, Hachioji, Tokyo, Japan

*Corresponding author: swkbys37@tamacc.chuo-u.ac.jp

\begin{abstract}
This paper has two aims: a) to describe how English is used as a lingua franca in Asia, and b) to discuss factors that are essential for successfully running a course collaboratively between two universities in different countries. First, I illustrate the ELT situation in Japan and hypothetical but plausible conversations among interlocutors with different proficiencies. Then, I present the conditions under which Japanese and Malaysian (or other) universities can implement an effective joint course where students can be expected to acquire genuine 'communicative competence.' I argue that relatively more proficient learners must make a concerted effort to engage in communicative activities in order for their less proficient interlocutors to persist in communicating in the lingua franca. Furthermore, all English speakers, whether they speak it as a foreign, second or even first language, should cultivate chances to interact with speakers with varied language backgrounds.
\end{abstract}

Keywords: Communicative competernce; power in communication; collaboration among institutes

(C) 2017 Penerbit UTM Press. All rights reserved

\subsection{INTRODUCTION}

English is learned in most parts of the world. We feel that it has truly become a lingua franca, at least in the academic world, and that the demand for its use with confidence is getting even more important every day. This tendency will not stop, and younger generations should be keen to learn this language, especially in a country like Japan, which cannot survive without communicating with other countries. In fact, a substantive number of people, not only students but also adults, seem to 'feel' that they must become more proficient in English. A lot of language schools operate successful businesses, which is clear when we see the many advertisements throughout the city and commercials on TV and the Internet. However, this situation appears not to have resulted in improved general proficiency of English for communication among Japanese citizens, even among university graduates. The Ministry of Education, Culture, Sports, Science and Technology (MEXT) has been trying to change the situation, but the effect seems rather limited.

There are surely a number of factors and a variety of reasons, but one clear reason exists for the apparent contradiction between people's experience and the government's wish. This is due to a mismatch between what MEXT thinks students should do and what students really do in practice, both in and out of English class. This mismatch can be further attributed to the fact that real demands for communication in English are generally lacking in most situations in Japan.

I suggest that project- and content-based interactive learning in English as a lingua franca is one of the best solutions, or maybe even the only solution, for this situation. This kind of learning should be designed in such a way that communication involves both fluent (including native and non-native) and non-fluent learners. Even native speakers of English are likely to benefit from experience with non-fluent speakers, by obtaining skills to draw information out of them in conversation. In present day real situations, when communication breaks down, we always appear to attribute the cause to those with inferior control over the language (at least in English discourse). However, this may reflect an abuse of language power in communication. Such breakdown is not solely the result of the weaker user's lack of production skills but also to the stronger user's lack of listening skills.

Face-to-face communication, or similar interaction through video-conferencing, will help to establish a better world by letting participants understand both their own and another participant's culture and identity, as well as respect for other people, consideration for how they feel, and sympathy with them.

Interactive communication is likely to reveal power differences among participants in a discourse, especially between fluent and nonfluent speakers, where the former has the advantage in that they they occupy the field of discourse and control the exchange of ideas. The latter may have fewer chances to express their own thoughts and consequently feel inferior to their interlocutors, at the mercy of the currency of interaction controlled by those interlocutors. Hence, in general, if fluent speakers are considerate and patient enough to invite less fluent speakers to participate in the discourse more effectively, those weaker participants would be happier, being encouraged to use the language in a better way, which will ultimately become comfortable for both parties. However, knowing how to communicate effectively with nonfluent learners is not necessarily given free.

In addition to a positive attitude, fluent speakers need experience. At the very least, reasonable consideration and patience are required. Some skills that fluent speakers need in such cases are documented in academic research (e.g., Gumperz, 1982; Hinnenkamp, 1987; Long, 
1983). They are certainly part of "communicative competence" in the target language and should be learned through communication, similar to how non-fluent learners acquire their target language and how to use communication strategies. Some characteristics of "foreigner talk" and "teacher talk," such as simplifying (Ferguson \& DeBose,1977), have been documented in speech by native speakers (Cazden, 1979, Cutrone, 2010, Henzl,1974) and non-native EFL teachers (Milk, 1990). However, it is very unlikely that ALL native (or fluent non-native) speakers have such skills to the same extent, as they are not needed for daily conversation with native speaker peers. In order for fluent speakers to gain the relevant skills for speaking in a way that encourages less-fluent speakers to communicate, fluent speakers should demonstrate a willingness to communicate with less fluent speakers, and this attitude is also likely to be brought about by experience. They should experience communicating with people with different levels of fluency and different varieties of English (cf. Hinnenkamp, 1987).

Here, the theory and practice of Language for Specific Purposes (LSP) is relevant. Sharing "specific purposes" should have an effect on participants in a conversation to overcome any difficulty in communication. Such purposes include not only career-related contents, but also genuine interest in scientific, academic, cultural and societal issues. The most important point is that communication in the target language should have a clear purpose so that genuine communication is required in a real situation. To implement such ideas into practice, students should have chances to meet one another, either directly or via Information and Communication Technology (ICT). I would like to present examples of two courses at Chuo University, Tokyo, that are run in collaboration with Universiti Teknologi Malaysia (UTM) and other partner universities.

This paper is structured as follows: first, I will illustrate some 'general' situations in classrooms in Japan and discuss just how (ir)relevant classroom activities are for the acquisition of English as a means for communication. Then, I will discuss issues concerning English as a lingua franca. After this, I will briefly describe the two courses at Chuo University and suggest that institutional collaborations have crucial roles to play for better language learning.

\subsection{GENERAL SITUATIONS IN JAPAN AND SECOND LANGUAGE ACQUISITION}

\section{Fake Goals}

I carried out an informal survey in a class at the end of the first term in 2015, where thirty-one students (participants), all majoring in English Studies, and studied an introductory unit on English linguistics taught by the present author. The question was what they wanted to achieve by the end of their first year at university. Their answers were divided into two groups: i) To get a better grade/mark on proficiency tests, such as TOEFL; or ii) to get ready to join a study-abroad program. Their answers disappointed me as I expected them to say something related with the real use of and communication in English.

In fact, although some students surely study English for better communication, others appear to just sit in class to get enough credits to graduate from the university. Needless to say, these students' stated purposes are neither to get better scores on proficiency tests nor to get ready to study abroad. This may sound pessimistic, but this is the situation. Thus, we have to consider what we teach and must carefully design curriculums and courses so that getting credits guarantees students' improvement in English proficiencies.

On the other hand, it might be fair to ask a related question to teachers and professors: Why do you teach a language? We teach because teaching is our job, but it is not merely for us teachers as breadwinners. We have something more important to do. We should help students improve their proficiency in English or their willingness to communicate (WTC) (McIntyre, Clément, Dörnyei, \& Noels, 1998), so that students will go on to lead an enjoyable and happy life. I believe every teacher should, explicitly or implicitly, support their students to improve their English skills and WTC.

In a multi-lingual society like Malaysia or the Philippines, proficiency in English may be directly related with socio-economic and cultural aspects of students' lives as well as be regarded as a reflection of their intelligence and academic effort. On the other hand, in Japan, for practical purposes, the Japanese language is THE language, and local people generally do not find it problematic if they lack English skills, except perhaps for winning competitions in educational situations, though some people may be aware of a need for proficiency in a lingua franca to widen their perspectives and social networks.

I repeat that English is taught in Japan to enhance students' ability for communication. Using English or communicating in English is, however, not a reality in the daily lives for most students - at least not for most of the students in the class I mentioned above, even though they attend more than a few classes where English is used as the only language for communication. They hardly have any chance to use English outside the classroom. This may reflect the fact that only one percent of the population in Japan uses English in their daily lives (Terasawa, 2015).

Using English in class and doing homework at home are hardly sufficient for students to acquire English required for any practical purposes, other than answering questions in end-term exams or getting a reasonably good mark on a proficiency test. If their goal is to pass the test, they study whatever is relevant for preparing for the test. This is cramming, not language-learning. Tests are certainly important, at least in Japanese culture, but learning for a test should not be confused with language learning. As is often said, a person good at using the target language is likely to gain a high score on a language proficiency test, but not necessarily vice versa.

No chance to use English outside the classroom is a real problem for language learning. All second language acquisition theories presuppose learners' use of the target language. Moreover, recent studies have shown that how much learners use a target language is closely correlated with their attainment (and probably along with their WTC): Many studies in second language acquisition (SLA) research have shown the length of time using the target language is even more important than the age when learners start learning the target language (Slabakova, 2016).

I suspect learners (and teachers) are not fully aware of the fact that what they do for getting a better score on a test may not be 'directly' related with SLA. The students I mentioned at the beginning in this paper are unlikely to have understood this fact, partly due to their lack of experience using English as a means for communication and partly due to their lack of meta-knowledge about their own ability in using language. Experience with communication is most important because, to repeat, only through the experience of communicating in the target language can they acquire knowledge for second language use. 


\section{Fake 'Communicative’ Activities: What Learners Do.}

Reading or listening for comprehension checking questions, speaking, writing, and interacting by filling in information gaps in a "communication" task in class are all "fake" communicative activities, because there is no genuine need to pursue a certain communicative goal - for a better relation or for a piece of information-in the target language. This does not mean that classroom activities have no meaning, but it means that they are insufficient: Reading activities should be for reading materials for their content (e.g., enjoying reading a novel or getting information from a document); listening activities should be for listening to materials for their content (e.g., enjoying listening to story-telling or getting an idea from a video clip on the web or gathering information from a radio news program); speaking activities should be for expressing content to someone (e.g., expressing how they feel when meeting someone from abroad or telling something that a hearer will need to know at some later point); writing activities should be for writing content to someone (e.g., texting to a person to exchange ideas and feelings or writing season's greetings to an old friend); and interacting with a person should be for exchanging information or sharing the time and space (e.g., for sharing ideas about some academic or social activities or for getting to know a person better by talking about a common interest). These are the communicative activities what should be done.

Students may not be 'parrots' - an often-used metaphor to describe them in class using the audio-lingual method-in a communicative approach based activity, but they may be 'puppets', which have strings on their limbs, given the contents and often the forms to use for communication. They do just what teachers have planned for them to do. Most "communicative activities" in English classes in Japan follow one plot in which the teacher explains the contents of a lesson, checks the students' comprehension, then students exchange information using the words, phrases, structures just learned, which is merely 'a citation game' (Yanase \& Koizumi, 2015). Activities such as role-play to practice interaction may be all right as practice, but they are different from participating in a discourse in the target language, where 'correct answers' are not given beforehand. In this game, students do not have to use their brains to think of what they want and/or need to communicate.

The citation game may be inevitable when learners are at an early stage of learning. English and Japanese are so distant from each other typologically. Shared vocabulary and rules are so limited that learners should learn rules and words in the target language. But using language in 'real' communication seems utterly lacking. Metalinguistic knowledge is not automatically turned into learners' procedural knowledge without relevant 'practice' in use (Wilkins, 1976), which is supported by neurolinguistic investigations (Paradis, 2009), and this 'practice' should include real communication in the target language. 'Real communication' has a purpose and should be done in the most effective language among participants in a conversation.

Learners certainly have chances to converse with peers in Japan. However, that is only realized as mock (puppet-to-puppet) communication, which lacks real purpose for communication and is unnatural. This kind of mock communication is different from, for example, discourse structures, including turn-taking or back-channeling, and in socio-linguistic aspects, such as when to use relatively more polite forms (cf. e.g., Shimizu, 2016).

\section{Activities Needed}

We teachers know, from daily experience, that learners do not necessarily acquire, learn, or even understand what is taught in class. There is a gap between what is taught-or what teachers believe is taught-and what learners acquire or use. A number of hypotheses and models have been proposed for SLA since Corder (1967) (cf. Gass, Behney, \& Plonsky, 2013), and, as Shibata (2016) correctly pointed out, all of these theories without exception, presuppose that learners learn a second language by using it. According to the Input Hypothesis (Krashen, 1985), comprehensible input has to be processed somehow. According to the Interaction Hypothesis (Long, 1983), negotiation in interaction is important, so interaction has to take place. In the Output Hypothesis (Swain, 1985), output is necessary, so production or use of the target language is important. There are a number of models / hypotheses offered, but none suggests that L2 use is not necessary for SLA. On the other hand, some type of metalinguistic knowledge is likely to be needed to attain better proficiency, but using the target language is at the center of language acquisition. This appears natural, but not trivial in an EFL environment.

In short, Japanese students in general appear to study 'English' for test taking or for earning credits at school, rather than for acquiring the language. This is mainly because they do not have to use English. In such conditions, making situations where using English to communicate with those whose L1s are not Japanese will help learners to acquire English as a second language. In such situations, communicative competence in the sense of Hymes (1972) can be acquired.

\subsection{ENGLISH AS A LINGUA FRANCA}

\section{Responsibility For Communication Breakdown}

In the introduction of this paper, I suggested that native (or near-native) speakers of English should learn how to communicate with nonfluent learners so that they can develop skills needed for successful communication. All participants should learn how to speak to one another in any discourse. None of the theories of SLA mentioned above (\$2.3), and, in fact, few newer theories of SLA and second language teaching, have discussed how fluent learners become better communicators through conversation with less fluent speakers. I consider this to be extremely important, especially for English as a lingua franca.

We should not expect L2 learners to attain native-like proficiency. Even after living in the United States for more than twenty years, working as a business person, a multilingual speaker who acquired English as an adult has clear non-native characteristics (Lardiere, 1998a, 1998b), and second language speakers have difficulty in the acquisition of certain morphemes even after a long exposure, especially when their first language is typologically distant from the target language (Johnson \& Newport, 1989, 1991). Recent studies show that a crucial element is daily use of the target language, but the situation does not change. It is extremely rare if not impossible for a non-native speaker to become a really fluent speaker in that language (Slabakova, 2016). Anyway, non-native speakers are forced to expend effort when they speak in the target language. Then, when communication needs to be successful in the world (of discourse) with participants with different language backgrounds, all participants, including native or near-native speakers, should be making effort. Moreover, we should expect native 
speakers to attain the communicative competence needed for successful communication with non-native speakers, which can plausibly be attained by most native speakers (although I have no data to support this). Data from some studies (see $\$ 3.2$ below) imply that native speakers need exposure to non-native English speakers so that they can communicate effectively.

The need for experience is not limited to communication between native and non-native speakers. Let us imagine a situation where none of the participants are native speakers of English, such as when Malaysian university students communicate with Japanese university students, as this actually happens through a TV video conference system (see Figure 2). If a Malaysian student speaks too fast, then the Japanese students cannot follow, and as you may be aware, less fluent speakers tend to conceal their lack of understanding, partly because they know they have less power in discourse (or appear not to care much, in fact). Sociolinguistically speaking, stronger participants may intervene in the flow of currency of conversation (Itakura, 2001). Consequently, if the Malaysian student does not pay much attention to the Japanese students' responses or fails to notice signals from them indicating their lack of understanding, the conversation may have less value than when all participants understand one another: Not only do Japanese students fail to get information and/or consolidation from that conversation, but the Malaysian student may fail to obtain relevant information from them. This is an unwanted situation for both the Malaysian and Japanese participants. How can we develop the skills needed for avoiding communication breakdown?

One way is to get involved in such communication and somehow try to find ways to overcome difficulties. This is probably the only way available now. In fact, although we know we somehow manage to communicate in a lingua franca, we do not know much about exactly how participants pick up relevant signals from the interaction. However, SLA studies and studies in World Englishes have revealed a number of phenomena common to L2 speakers with divergent L1 backgrounds (see e.g., Gass, Behney, \& Plonsky, 2013) and speakers of different varieties of English (see Kirkpatrick \& Deterding, 2011 for summary). Both kinds of research show that certain morpho-phonological elements, e.g., tense marking on verbs in English, are used differently by native speakers in the societies where most people have been native speakers of English for generations ("Inner Circle" in Kachuru, 1992) and those in the other parts of the world. Some may say that native (and near-native) speakers are able to tell intuitively where weaker users have problems and solve the problem by themselves. However, this is not always plausible. Let us turn to a few examples in the next subsection.

\section{Examples of Communication Breakdown And Misunderstanding}

Bateson (1935/1972/2000) coined the term "complementary schismogenesis" to describe a certain type of difficult situation when persons with different cultural/discourse backgrounds meet. A hypothetical example is given by Tannen (2006) to illustrate this: An American man asks a Japanese woman if she would like to go to lunch. They exchange utterances, and toward the end, the American man asks the Japanese woman, "Are you trying to tell me you never want to have lunch with me, or should I keep asking?" This clearly shows this man does not understand the message given by the woman, who quite clearly says no, or he does understand the message but wants to hear a more clearly explicit response. Toward this last question, the Japanese woman still answers "Gee, well, I don't know, lunch, you know...," again. The Japanese woman rejects the American man's offer by showing her lack of interest, but according to this American man's discourse rule, what she shows is not an adequate rejection. It seems that the Japanese woman thinks it is rude to say no to the request (according to Tannen's understanding of Japanese women's behavior), and that she would never say no.

In this example, the Japanese woman is good at speaking grammatically well-formed English sentences, but she may not be aware of the relevant rule in discourse structures that the American man expected to be used or may be aware but she chooses not to follow the rule. Simply put, she should have said no, or something like, "I think I do not feel like going to lunch with you; I prefer to eat by myself." Here, we should be aware that, in fact, the American man should have (unconsciously) known how discourse is being structured between them (cf. Brouwer \& Wagner, 2004). If he had had a reasonable amount of experience with this kind of speech act with a person from a different language and cultural background, he might have understood the message.

We should be aware that this is merely a hypothetical example, and there are a number of idiosyncratic differences among speakers. The American man may be too pushy or put too much emphasis on positive politeness (Brown \& Levinson, 1987), and there certainly exist other types of American men. However, what I would like to emphasize is that ONLY the less fluent (or less dominant) speaker (in this case, the Japanese woman) is usually, if not always, to blame and expected to behave in a similar, if not the same way as a stereotypical American woman would in this kind of situation (as I did above). This is certainly not the only solution. It would be easier for native speakers to accommodate themselves to the situation for successful communication.

Let us consider another example which is the use of back channeling. Japanese speaking learners of English often use back channeling, and in fact, they may signal back channeling in English conversation more than is appropriate for English, which will likely disturb conversation with native speakers (Maynard, 1997, see also Marki-Tsilipakou, 1994 for various functions of back channeling). This is because back channeling is generally regarded as an expression of rapport between interlocutors in Japanese while it is often the start of an unwelcome interruption in conversations among native speakers of English. Consequently, even though Japanese participants try to show positive attitudes toward native speakers, native speakers may feel uncomfortable with the Japanese speakers' behavior (Maynard, 1997). In this case again, we tend to think that Japanese people should learn how to use back channeling in 'English.' However, the conversation in this situation is an interaction where English is used as a lingua franca, and hence it is fair to say that not only Japanese speakers but also American English L1 speakers should understand that L2 speakers' use (and non-use) of back channeling may reflect their 'polite' affirmative attitude toward making conversation. In short, all participants should be aware of differences.

The last example I would like to refer to is the value of 'producing utterances.' Apart from the discourse structures in utterances I mentioned above, the quantity and quality of utterances expected of each participant in a conversation may be different from culture to culture. This may be reflected in learners' behavior in producing English in general. Ishikawa (2016) shows clear differences among the amount of oral production in his telephone interview in accordance with learner proficiency in the target language (English) and in differences in L1 background. Ishikawa compared the numbers of words per minute produced by Japanese and Chinese speaking learners of English (150 participants in each group) and found the Japanese learners produced fewer utterances when they were less proficient; and that the amount gradually increased in accordance with proficiency. On the other hand, Chinese speaking learners of English did not show such differences in the amount of production in accordance with English proficiency. All Chinese groups produced more utterances than the most advanced Japanese group on average, as shown in Figure 1. In other words, Chinese speak more fluently (or at least a greater number words per minute) no matter how proficient they are. 


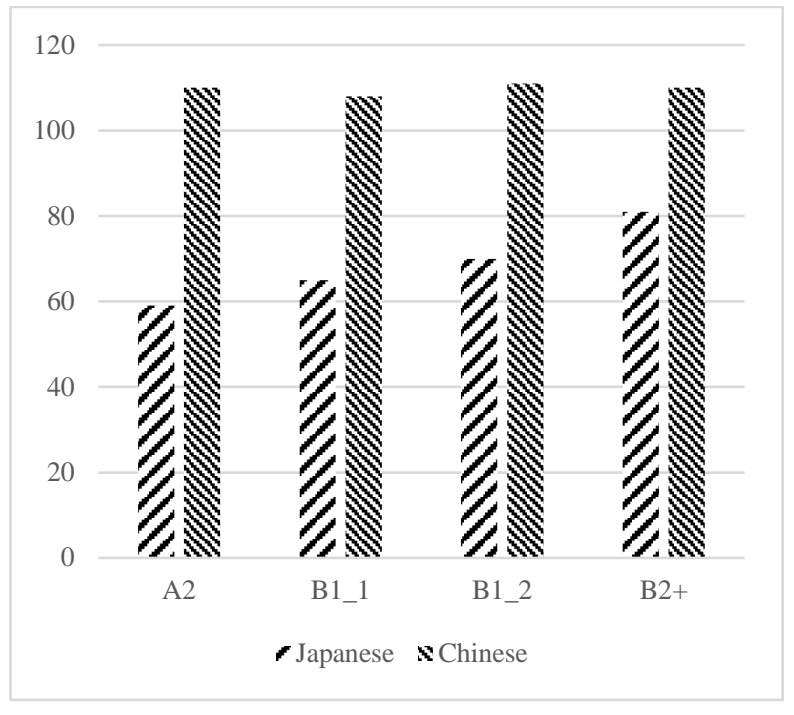

Figure 1 The mean numbers of words per minute (cited from Ishikawa, 2016)

We have to be careful how we interpret the data. One way is that Japanese speaking learners are not good at uttering English words because they cannot speak in English very well, but there are other ways to interpret this finding. Japanese may prefer keeping silent over uttering something clearly different from the target language while Japanese may be more tolerant of silence than Chinese, so that they can avoid making errors (cf. Schachter, 1974). Japanese are perhaps reticent rather than talkative even in a telephone interview. Although we do not know how or even whether this difference might reflect their L1 behavior, it should be clear that Japanese are modest in making utterances in English in general. When this moderate behavior appears in conversation, it is likely to be interpreted as a lack of speaking skill. Then, if communication breaks down in conversation, it is such modest Japanese participants who are to blame. But if we assume that all participants are responsible to construct a discourse, non-Japanese participants, who are less tolerant of silence, may need to draw out utterances from the Japanese participants, who may nevertheless have something valuable in their heart and mind. In order to do this, more proficient speakers, native- or non-native speakers, may well practice this through communicating with less proficient speakers and through experience talking with Japanese speakers.

\subsection{REFLECTION ON EDUCATION: EXAMPLE COURSES}

So far, problems with both language education and with communication in English as a lingua franca have been discussed: i) Japanese students in general appear to study 'English' for test taking or for earning credits at school, rather than for acquiring the language ii) although all participants in a communicative exchange are responsible for communication breakdown when it occurs, the responsibility appears to be typically placed solely with less proficient speakers. This is problematic when we think of the current world, where mutual understanding among people is needed to create a more peaceful world. I suggest that creating more chances for L2 speakers with different proficiencies and different L1 backgrounds to meet one another may begin to solve these problems. In this section, I will describe two courses at my university. In one course (Advanced Communication), English speakers from different language backgrounds meet through ICT.

\section{Advanced Communication}

One course consists of fifteen 90-minute classes meeting once a week at the Faculty of Letters, Chuo University. 'Advanced Communication' was an elective course open to all students at the university. The purpose of this course was for students to "acquire the skills and attitudes for making presentations by activities with students at partner universities abroad." For the autumn 2016 course, twenty students were selected among applicants based on short essays and their GPA. The syllabus of the course is given in Table 1.

This course was divided into three units: A, B, and C. In each unit, we used ICT systems to communicate with students abroad and to record video of the students' performance. 
Table 1 Syllabus of advanced communication

\begin{tabular}{lll}
\hline Unit & week & Class Contents \\
\hline & 1 & Preparation for eChat \\
& 2 & Preparation for eChat \\
A & 3 & $\begin{array}{l}\text { eChat with students at the Australian National University } \\
\text { eChat with students at the Australian National University }\end{array}$ \\
& 4 & eChat with students at the Australian National University \\
& 5 & Review of eChat \\
\hline & 6 & Preparation for TV collaboration \\
& 7 & Preparation for TV collaboration \\
& 8 & TV collaboration with Universiti Teknologi Malaysia \\
& 10 & TV collaboration with Universiti Teknologi Malaysia \\
& 11 & TV collaboration with Universiti Teknologi Malaysia \\
& 12 & Review of presentations \\
& 13 & TV collaboration with Universiti Teknologi Malaysia \\
\hline \multirow{2}{*}{ C } & 14 & preparation for video recording \\
& 15 & video recording (individual activity)
\end{tabular}

The main activity in unit A was chatting verbally with students at the Australian National University (ANU) who are studying intermediate Japanese. During the first two class sessions, students prepared for their video chats with ANU students. Students learned and practiced speaking and listening skills, and prepared for the interactions with ANU students by searching for relevant information through web searches and books. Three classes of unit A were chatting via the Internet. We used a chat system based on Adobe Connect at ANU, which allowed two to four students to communicate in one virtual room (see Figure 2). The topic for each class was taken from the textbook used in the class at ANU. All students at Chuo University read the relevant material from the textbook before the class and did some research to get ready for exchanging information activity. The topics included 'convenience stores and vending machines in Japan,' 'history of Japan,' and 'Recycle, Reduce and Reuse in Japan.' At the beginning of each session, students negotiated with one another for chatting and decided how long they would use English and how long they would use Japanese. All students at Chuo University wrote and submitted their review reports to the instructor (i.e., the author) through a website after each eChat class.

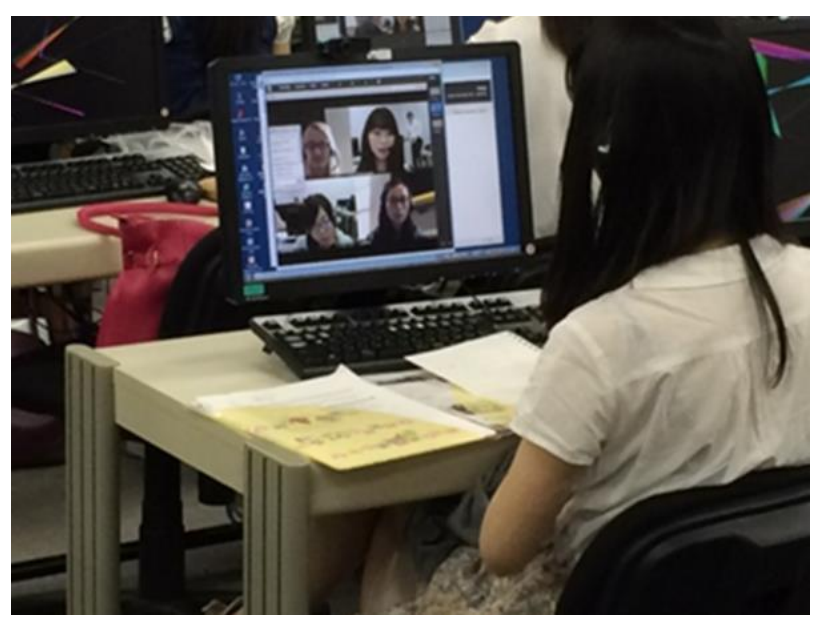

Figure 2 A scene of eChat

The main activity in unit B was presentations and discussion with students at the University Technologi Malaysia (UTM). Students at Chuo University described certain aspects of Japanese society and culture to those who were studying Japanese at UTM. During the first two class sessions (weeks 7 and 8), students learned how to make presentations following a textbook based on TED talks. From week 9 to 13 (except week 12, which happened to be a holiday in Malaysia), we used a TV conference system to connect classrooms. A scene is given in Figure 3, where a student is presenting his talk to the TV camera and the class in Japan. Two images projected on the side screen at the upper 
left corner. One of them showed the class at UTM (left) and the other showed the picture of the student's presentation being shown to UTM students. A TV monitor on the desk (right in Figure 3), facing the presenter, showed the same two images to the presenter.

One student talked for around five minutes, and then question and answer session took about five more minutes. After the students at Chuo University presented their talks and answered questions, the UTM students talked about various aspects of Malaysian life, culture, and society, such as food, clothes, festivals, and transportation. Topics of our students' talks covered various aspects of Japanese life, society and culture: cuisine, music, tourism, transportation in Tokyo, public baths, physical education, school uniforms, identity, senior-junior relationships, and the coming-of-age ceremony. Every student decided her/his own topic, carried out research, and delivered a TED-like talk.

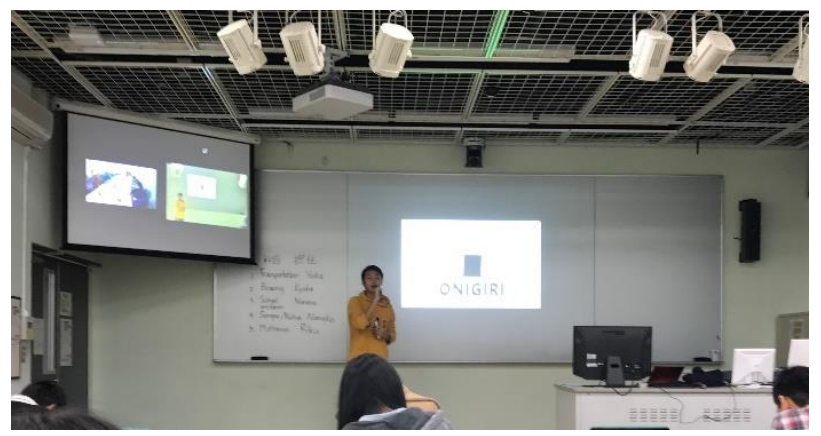

Figure 3 A scene of TED-like presentation

During the last two class sessions in unit $\mathrm{C}$ (and sometimes outside class), the students recorded their own talks, revised versions of their TED-like talks in a recording studio at the university. They submitted the video clips for credit through our web system .

You may have noticed that all students at our partner universities study Japanese language, so it is natural to assume that they are interested in Japan and Japanese culture. Our students provide them with real information about Japan through their own eyes, which is of high value to students of the same generation. An email from the instructor at UTM said that there were many aspects of life in Japan that even he did not know about.

\section{Global Studies (Linguistics)}

Global Studies is a category of course where professors take groups of undergraduate students abroad to investigate issues related to their majors. During the school/fiscal year of 2016, there were twelve courses, which included linguistics, history, sociology, informatics, psychology, and education. The course in linguistics described below is one of these courses.

This course, offered in the autumn term 2015 (from September 2015 to February 2016), was open only to students who majored in English linguistics and was based on collaboration with partner universities. The main activity of this course is to make poster presentations based on research at a student conference jointly organized by the Language Academy, UTM in February 2016. The main event was the students' visit to Malaysia and Singapore to participate in the conference at UTM. In addition, the students enjoyed a number of activities, including short visits to two primary and middle schools. Titles of poster presentations from students at UTM, Chuo University and a few other institutions are given below.

- L1 Influence on Japanese Learners' Acquisition of English Passive

- Do Japanese Learners of English Recognize Stage-Level and Individual-Level Collocation Restrictions?

L2 Acquisition of English VP-Ellipsis: A Preliminary Study

- Merge(there) within DP: Considerations From Agree and Left Branch Extraction

Speaking Anxiety and the Use of Affective Strategy

- The Secondary School Students' Usage of English Learning Websites to Self-Correct Writing Errors

- UTM Graduating Students' Perceptions of the Task Difficulty of the Oral Interaction Tecs

- The Test of English Communication Skills (Tecs): Assessing the Rubric for Language and Interactive Ability

- Challenges Faced by Malaysian English Teachers When Trained by Native -Speaking Mentors of English

- Medical Tourism Related Websites in Southeast Asia: Constructing Trust via Focal Themes

- Socio Cultural Adaptation of International Graduate Student in Malaysia

- Language Learning Strategies Influencing Autonomy in Learning Japanese

- Mapping the Structure of HIV Counseling in Malaysia

Systematic Functional Multimodal Analysis of Tourism Promotional Videos

- Teacher Trainees' Practices of Teaching Writing in Primary Setting

- Local Skincare Products Advertisements: An Evolution or a Revolution

- Text Structure as a Scaffolding Tool for Reading Comprehension

The Narrative Structure of Malay Storytelling Language and Communication

- A Functional Perspective on the Representation of Experience in Professional Forestry Report: Insights on the Malay Language

- Exploring CoChELit 
As Figure 4 shows, the students presented their work in a poster presentation. This method of presentation worked very well because students could rely on the poster when they had difficulty explaining something technical in English. In addition, making a poster to present their studies is good (and genuine) practice for writing. Presenting the poster, exchanging questions, answering to the comments were surely "real" communication. Moreover, the students kept the poster after the conference and referred to it for further study after they return to Japan.

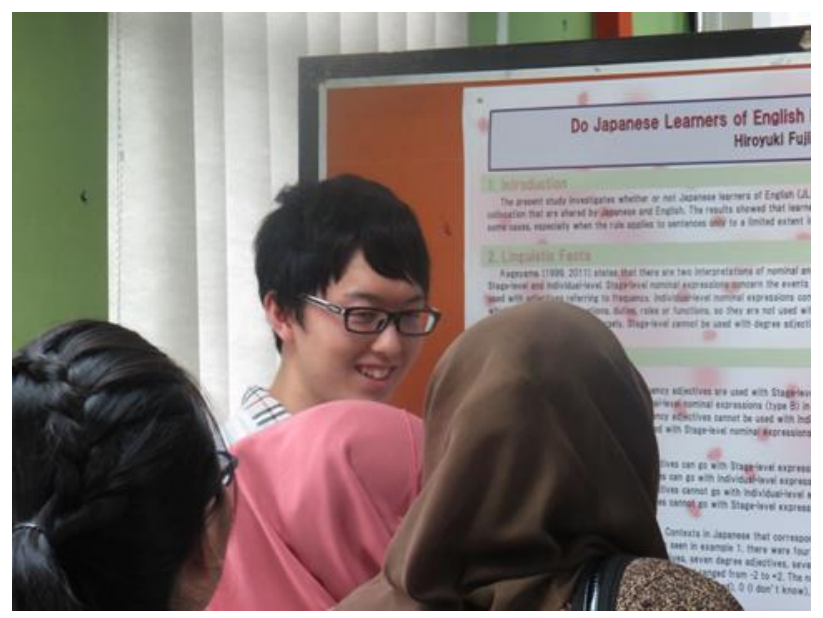

Figure 4 A scene in the student conference

Practical Issues

The two courses mentioned earlier were surely beneficial to students, but they require a lot of preparation and specialized conditions that do not exist in planning an 'ordinary' classroom activity. Among them, three issues are worth mentioning here. One is a budgetary issue. Advanced Communication does not appear to require much in terms of substantive additional budget once the course has been set up. Global Studies, on the other hand, needs funding for travel. Support from the university is limited, hence, students mainly fund the trip themselves. The problem is the budget for teachers. So far, this has been provided by Chuo University.

Another challenge is the fact that this kind of collaboration takes a lot of time and energy for management. Hence, honestly speaking, there is not much time left for the research that I am expected to do as my (main) job. This problem may seem personal, but it is not trivial: Innovative programs in education require some systematic - moral and/or financial-support from the university. In my case, I feel the benefit I receive exceeds the cost associated with carrying out these courses, thanks to my colleagues and students. Therefore, I think it is my job to maintain and expand these types of programs as a sort of my duty — Life may not be easy, but it is enjoyable.

Last but not least, it is extremely important to mention that a number of academic and non-academic staff members have been involved in the collaborations with partner universities, including teachers/instructors of the class, and non-academic staff members at the technical support center, the faculty and department offices, and the international offices. Moreover, even more support is needed from partner universities.

It is clear that we need to collaborate with partner universities to create situations where Japanese students use English as a 'real' means of communication. Although I have taught the courses mentioned above, the management is rather personal at the moment. We need some systematic support to maintain and further improve these courses.

\subsection{SUMMARY AND FUTURE DIRECTIONS}

In this paper, I first suggested that most Japanese students study 'English' for tests and not for communication or for any kind of real use and that what they do in 'communicative tasks' is in fact 'fake' communication. We really have to create situations where English is used as a lingua franca, and expose Japanese students to that kind of situation so that they develop authentic communication skills. Then, I argued that all participants should acquire better communicative competence, emphasizing that native (and near-native) speakers should experience communication with less fluent speakers of English. This is because native(-like)-speakers may misinterpret the Japanese speakers' behavior: For example, back channeling may reflect their positive attitude toward the conversation without any intention to interrupt. I also briefly described two courses I teach at my university, through which Japanese students meet non-Japanese students.

You may have noticed that these two courses constitute cases of Language for Specific Purposes (LSP) in the sense that they are contentbased and goal-oriented in that English is used as a means of communication. Japanese university students in Advanced Communication have information that is of interest to students at ANU and UTM. That is, they have knowledge of Japanese culture and society as a member of today's younger generation living in Japan. The students in Global Studies have something to present in a student conference, as illustrated by the list of poster titles. So far, however, I have had no systematic review of these courses. Any effects on participants' development of or change in communicative competence should be examined in the future. I speculate that there are measurable effects on students' attitudes toward (non)native speakers' behavior, meta-knowledge of discourse/pragmatic structure, and other factors involved in the discourse.

Lastly, I would like to suggest that instructors/teachers/professors at universities in ASEAN countries may be interested in collaborating with Japanese universities, where communication is carried out in English (or possibly another language) as a lingua franca. It should be clear that both Japanese and non-Japanese students will benefit from this kind of collaboration. It seems to me that we need to create opportunities 
where university students meet others with different first languages and different cultural backgrounds. In Europe, cultural exchange and mobility programs have been carried out across a lot of institutions. We do not necessarily have to follow what the Western world does, but it seems to me that university students should have wider perspectives than they do at the moment, and the kind of courses described in this paper provide them with occasions for the experience of real communication. From a number of perspectives, such as the cost of transportation, time-differences, and cultural and historical backgrounds, it appears easier and even requisite for institutions in Asian countries, as well as Australia, to collaborate with one another so that they can educate a younger generation with wide and deep interest of the world.

\section{Acknowledgements}

This research was supported by a Chuo University Personal Research Grant. An earlier version (Wakabayashi, 2016) was presented at the International Language for Specific Purposes Seminar 2016 (LSP2016): Insights and Innovations, at Razak Tower, Universiti Teknologi Malaysia Kuala Lumpur, 26-27 July 2016. My travel to this conference was supported by the Japan Foundation, for which I am extremely grateful. I would also like to thank Dr. Abdul Halim Abdul Raof, Dr. Nor Liza BT. Haji Ali, and Mr. Kumaraguru Rayamah at UTM for their kind support and the audience at LSP2016 for their comments. Special thanks go to Professor John Matthews at Chuo University for his valuable comments on the contents and the English. All shortcoming are of course mine.

\section{References}

Bateson, G. (1935/1972/2000). Culture Contact and Schismogenesis, in Bateson, G. (ed.) Steps to an Ecology of Mind ( 61-72). Chicago University Press.

Brouwer, C. E. \& Wagner, J. (2004). Developmental Issues in Second Language Conversation. Journal of Applied Linguistics, 1, $29-47$.

Brown, P. \& Levinson, C. (1987). Politeness: Some Universals in Language Usage. Cambridge: Cambridge University Press.

Cazden, C. (1979). Language in Education: Variation in the Teacher Talk Register. In J. Alatis \& G. Tucker (Eds.), Georgetown University Round Table on Languages and Linguistics 1979. Washington, D.C.: Georgetown University Press

Corder, S. P. (1967). The Significance of Learners' Errors. International Review of Applied Linguistics, 5, 161-170.

Cutrone, P. (2010). The Backchannel Norms of Native English Speakers: A Target for Japanese L2 English Learners, Language Studies Working Papers, 2, 28-37. University of Reading.

Ferguson, C. \& C. DeBose. (1977). Simplified Register, Broken Language, and Pidginization.In A. Valdman (Ed.), Pidgins and Creoles. Bloomington: Indiana University Press.

Gallo, K. (2014). TED Kyôi-no Purezen: Hito-o Hikituke Kokoro-o Ugokasu 9-tu No Hôsoku [Talk Like TED: The 9 Public-Speaking Secrets of the World's Top Mind.] Tokyo: Nikkei BP.

Gass, S. M., Behney, J., \& Plonsky, L. (2013). Second Language Acquisition: An Introductory Course. 4th ed. New York: Routledge.

Gumperz, J. (1982). Language and Social Identity. Cambridge: Cambridge University Press.

Henzl, V. (1974). Linguistic Register of Foreign Language Instruction. Language Learning, 23, 207-222.

Hinnenkamp, V. (1987). Foreigner Talk, Code Switching and the Concept of Trouble, in Knapp, K., Enninger, W. \& Knapp-Potthoff, A. (eds.), Analyzing Intercultural Communication. The Hague: Mouton de Gruyter.

Hymes, D. H. (1972). On Communicative Competence. In Pride, J. B., \& Holmes, J. (Eds.), Sociolinguistics, 269-293. Baltimore, MD: Penguin Books.

Ishikawa, S. (2016). Ninozin Eigo Gakusyusya-no L2 Eigo-no Hatuwaryo: Bogo Wasya Oyobi Aziaken Gakusyusya-to-no Hikaku [A Quantitative Study on L2 English Speeches by Japanese Learners-a Comparison with Native Speakers and Other Asian Learners-] [Niti-eibunkakenkyu] Journal of The Association for Japanese and English Language and Culture, 5, 15-26.

Itakura, H. (2001). Describing Conversational Dominance. Journal of Pragmatics, 33, 1859-1880.

Johnson, J. S. \& Newport, E. (1989). Critical Period Effects in Second Language Learning: The Influence of Maturational State on the Acquisition of English as a Second Language. Cognitive Psychology, 21, 60-99.

Johnson, J. S. \& Newpport, E. (1991). Critical Period Effects on Universal Properties of Language: The Status of Subjacency in the Acquisition of a Second Language. Cognition, 39, 215-258.

Kachuru, B. B. (1992). Teaching World Englishes, in Kachuru, B. B. (ed.) The Other Tongue: English Across Cultures. 2nd Ed. Urbana and Chicago: University of Illinois Press.

Kachuru, Y. \& Smith, L. E. (200). Cultures, Contexts, and World Englishes. New York and London: Routledge.

Kirkpatrick, A. \& Deterding, D. (2011). World Englishes, in Simpson, J. (ed.) The Routledge Handbook of Applied Linguistics (pp. 373-387). London and New York: Routledge.

Krashen, S. (1985). The Input Hypothesis: Issues and Implications. New York: Longman.

Lardiere, D. (1998a). Case and Tense in the 'Fossilization' Steady State. Second Language Research, 14, 1-26.

Lardiere, D. (1998b). Dissociating Syntax from Morphology in a Divergent L2 End-State Grammar. Second Language Research, 14, $359-375$.

Long, M. H. (1983). Native Speaker/Non-Native Speaker Conversation and the Negotiation of Comprehensible Input. Applied Linguistics, 4, 126-141.

Marki-Tsilipakou, M. (1994). Interruption Revisited: Affiliative v.s. Disaffiliative Intervention. Journal of Pragmatics, 21, 401-426.

Maynard, S. K. (1997). Analyzing Interactional Management in Native/Non-native English Conversation: a Case of Listener Response. International Review of Applied Linguistics, 35, 37-60.

McIntyre, P. D., Clément, R., Dörnyei, Z., \& Noels, K. (1998). Concepturalizing Willingness to Communicate in a L2: A Situational Model of L2 Confidence and Affiliation. Modern Language Journal, 82, 545-562.

Milk, R. D. (1990). Can Foreigners Do "Foreigner Talk"?: A Study of the Linguistic Input Provided by Non-Native Teachers of EFL. Texas Papers in Foreign Language Education, 1, 274-288.

Paradis, M. (2009). Declarative and Procedural Determinants of Second Languages. John Benjamins.

Reed.W. (2014).Sekaisaikô no purezenzyutu [World class speaking].Tokyo Kadokawa.

Schachter, J. (1974). An Error in Error Analysis. Language Leaning, 24, 205-214.

Shibata, M. (2016). Dai Ni Gengo Syûtoku, Eigokyôiku, Ringafuranka Eigo-no Siten-kara Kangaeru Hi-bogowasya Eigo. [Non-Native Speakers' English from the Perspectives of Second Language Acquisition, English Language Education, and English as a Lingua Franca]. Paper presented at the Japan Second Language Association Early Spring Seminar 2016, 19 June, 2016 at Kyoto Women's University.

Shimizu, T. (2016). Kokoro-o Ugokasu Eikawa no Sukiru. [Politeness: The Key to Successful Communication.] Tokyo: Kenkyusha.

Slabakova, R. (2016). Second Language Acquisition. Oxford: Oxford University Press.

Swain, M. (1985). Communicative Competence: Some Roles of Comprehensible Input and Comprehensible Output in its Development. In S. Gass \& C. Madden (Eds.), Input in Second Language Acquisition, 235-253. Rowley, MA: Newbury House.

Tannen, D. (2006). Language and Culture, in Fasold, R. W. \& Conner-Linton, F. (eds.), An Introduction to Language and Linguistics, 343-372. Cambridge University Press. 
Terasawa, T. (2015). “Nihon-zin to Eigo"-no Syakaigaku [Sociology for “Japanese People and English."] Tokyo: Kenkyusha.

Yanase, Y. \& Koizumi, K. (2015). Syôgakkô-kara-no Eigo Kyôiku-o Dôsuru-ka.[What to Do with English Language Education from Primary School]. Tokyo: Iwanami Shoten.

Wakabayashi, S. (2016). Innovation in Language Programs in the Era of Globalization. Paper presented at 10th Language for Specific Purposes Seminar (LSP2016), 26 July 2016, at Universiti Technologi Malaysia, Kuala Lupur

Wilkins, D. A. (1976). Notional Functional Syllabus. Oxford University Press. 